\title{
Application of a new scheme of cloud base droplet nucleation in a spectral (bin) microphysics cloud model: sensitivity to aerosol size distribution
}

\author{
Eyal Ilotoviz and Alexander Khain \\ Department of Atmospheric Sciences, The Hebrew University of Jerusalem, Jerusalem, Israel \\ Correspondence to: Alexander Khain (alexander.khain@mail.huji.ac.il)
}

Received: 17 June 2016 - Published in Atmos. Chem. Phys. Discuss.: 8 July 2016

Revised: 22 October 2016 - Accepted: 24 October 2016 - Published: 17 November 2016

\begin{abstract}
A new scheme of droplet nucleation at cloud base is implemented into the Hebrew University Cloud Model (HUCM) with spectral (bin) microphysics. In this scheme, supersaturation maximum $S_{\max }$ near cloud base is calculated using theoretical results according to which $S_{\max } \sim$ $w^{3 / 4} N_{\mathrm{d}}^{-1 / 2}$, where $w$ is the vertical velocity at cloud base and $N_{\mathrm{d}}$ is droplet concentration. Microphysical cloud structure obtained in the simulations of a midlatitude hail storm using the new scheme is compared with that obtained in the standard approach, in which droplet nucleation is calculated using supersaturation calculated in grid points. The simulations were performed with different concentrations of cloud condensational nuclei $(\mathrm{CCN})$ and with different shapes of $\mathrm{CCN}$ size spectra. It is shown that the new nucleation scheme substantially improves the vertical profile of droplet concentration shifting the concentration maximum to cloud base. It is shown that the effect of the CCN size distribution shape on cloud microphysics is not less important than the effect of the total CCN concentration. It is shown that the smallest CCN with diameters less than about $0.015 \mu \mathrm{m}$ have a substantial effect on mixed-phase and ice microphysics of deep convective clouds. Such CCN are not measured by standard CCN probes, which hinders understanding of cold microphysical processes.
\end{abstract}

\section{Introduction}

Droplet concentration is the key microphysical parameter that affects precipitation formation and radiative cloud properties (Pruppacher and Klett, 1997). The droplet concentra- tion determines major microphysical cloud properties such as height of precipitation onset and type of precipitation (liquid, mixed phase, and ice) (Khain et al., 2008; Khain, 2009; Freud and Rosenfeld, 2012; Tao et al., 2012). Droplet concentration is determined by concentration and size distribution of aerosol particles (APs) and by the maximum value of supersaturation near cloud base $S_{\max }$. $S_{\max }$ is reached at a few tens of meters above cloud base (Rogers and Yau, 1996). The vertical grid spacing of most cloud-resolving models is too coarse to resolve this maximum. This can lead to errors in determination of droplet concentration. Therefore, it is desirable to parameterize the process of droplet nucleation near cloud base. One approach to the parameterization is based on lookup tables developed using precise 1-D parcel models (e.g., Segal and Khain, 2006). The other approach is based on analytical calculation of supersaturation maximum, $S_{\max }$, near cloud base. This approach has been developed in several studies using various assumptions concerning cloud condensation nuclei (CCN) activity spectra (Ghan et al., 1993, 1997; Bedos et al., 1996; Abdul-Razzak et al., 1998; Khvorostyanov and Curry, 2006; Cohard et al., 1998; Abdul-Razzak and Ghan, 2000; Fountoukis, 2005; Shipway and Abel, 2010). In these studies calculation of a supersaturation maximum is reduced to solving a complicated integrodifferential equation assuming different expressions for CCN activation spectra. The parameters of activation $\mathrm{CCN}$ spectra, as well as the concentration and shape of the CCN size distributions, are often prescribed in atmospheric models and assumed to be invariant over time. The results and a comparison of these approaches are presented by Ghan et al. (2011).

In cloud models with a comparatively high resolution (Kogan, 1991; Khain et al., 2015), supersaturation $S_{\mathrm{w}}$ is calcu- 
lated explicitly at each grid point. In these bin microphysics models APs playing the role of $\mathrm{CCN}$ are described using aerosol size distribution functions containing several tens of size bins. The value of supersaturation is used to calculate the critical radius of APs using the Köhler theory. All CCN with sizes exceeding this critical value are activated to droplets. This approach will be referred to as the standard approach (ST), where supersaturation maximum near cloud base is not resolved and the vertical profile of supersaturation may not contain such maximum. It leads to underestimation of droplet concentration in clouds, at least in their low part.

In a set of studies by Pinsky et al. $(2012,2013,2014)$ formation of profiles of supersaturation and of droplet concentration was investigated both analytically and by means of a high-precision model of an ascending adiabatic parcel. Pinsky et al. (2012) proposed a simple method of calculating $S_{\max }$ near cloud base for monodisperse aerosol size distribution. The detailed test showed that the method can be applied to any CCN spectrum. Pinsky et al. (2014) gave a theoretical basis for such conclusion by calculating droplet concentrations using multidisperse size spectra of APs. The method of calculating droplet concentration near cloud base using $S_{\max }$ will be referred to as new approach (NA).

In this study we investigate the effects of application of NA on the microphysics of midlatitude deep convective clouds (hail storm) using the Hebrew University Cloud model (HUCM) with spectral-bin microphysics (SBM). The effect of the new approach is investigated in simulations with different parameters of $\mathrm{CCN}$ activation spectra.

\section{Model description}

The HUCM is a 2-D, nonhydrostatic SBM model with microphysics based on solving a system of equations for size distributions of liquid drops, three types of pristine ice crystals (plates, columns, and dendrites), snow/aggregates, graupel, hail, and partially frozen or "freezing drops". Each size distribution is discretized into 43 mass-doubling bins, with the smallest bin equivalent to the mass of a liquid droplet of radius $2 \mu \mathrm{m}$. APs playing the role of $\mathrm{CCN}$ are also defined on a mass grid containing 43 mass bins. The size of dry $\mathrm{CCN}$ ranges from 0.005 to $2 \mu \mathrm{m}$.

Primary nucleation of each ice crystal type is described using Meyers et al. (1992) parameterization. The type of ice crystals is determined depending on temperature range where the particles arise (Takahashi et al., 1991). Secondary ice generation is taken into account during riming (Hallett and Mossop, 1974). Collisions are described by solving the stochastic collection equations for the corresponding size distributions using the Bott (1998) method. Heightdependent, gravitational collision kernels for drop-drop and drop-graupel interactions are taken from Pinsky et al. (2001) and Khain et al. (2001); those for collisions between ice crystals are taken from Khain and Sednev (1995) and Khain et al. (2004). The latter studies include the dependence of particle mass on the ice crystal cross section. The effects of turbulence on collisions between cloud drops are included (Benmoshe et al., 2012). The collision kernels depend on the turbulence intensity and changes over time and space.

The time-dependent melting of snow, graupel, and hail as well as shedding of water from hail follows the approach suggested by Phillips et al. (2007). We have implemented liquid water mass in these hydrometeor particles that is advected and settles similarly to the mass of the corresponding particles. As a result, these particles are characterized by their total mass and by the mass of liquid water (i.e., the liquid water mass fraction). The liquid water fraction increases during melting. As soon as it exceeds $\sim 95 \%$, the melting particles are converted to raindrops. The process of time-dependent freezing is described according to Phillips et al. (2014, 2015). The freezing process consists of two stages. The first nucleation stage is described using the parameterization of immersion drop freezing proposed by Vali (1994) and Bigg (1953). Drops with radii below $80 \mu \mathrm{m}$ that freeze are assigned to plates, whereas larger drops undergoing freezing are assigned to freezing drops. The freezing drops consist of a core of liquid water surrounded by an ice envelope. Time-dependent freezing of liquid within freezing drops is calculated by solving the heat balance equations that take into account the effects of accretion of supercooled drops and ice particles. Collision between freezing drops and other hydrometeors leads either to the freezing drops category if the freezing drop is larger than its counterpart. Otherwise, the resulting particle is assigned to the type of counterpart. Once the liquid water fraction in a freezing drop becomes less than some minimal value $(<1 \%)$, it is converted to a hailstone. Hail can grow either by dry growth or by wet growth (Phillips et al., 2014, 2015). Accordingly, liquid water is allowed in hail and graupel particles at both positive and negative temperatures. The shedding of water in wet growth is also included.

Water accreted onto aggregates (snow) freezes immediately at temperatures below $0{ }^{\circ} \mathrm{C}$, where it then contributes to the rimed fraction. This rimed mass distribution is advected and settles similarly to the snow masses. Riming mass increases the density of the aggregates. As the bulk density of snow in a certain mass bin exceeds a critical value $\left(0.2 \mathrm{~g} \mathrm{~cm}^{-3}\right)$, the snow from this bin is converted into graupel. The appearance of water on the surface of hailstones as well as an increase in the rimed fraction of snowflakes affects the particle fall velocities and coalescence efficiencies.

The initial size distribution of CCN (at $t=0$ ) is calculated using the empirical dependence (i.e., the Twomey formula) of concentration $N_{\mathrm{CCN}}$ of activated $\mathrm{CCN}$ on supersaturation $S_{\mathrm{w}}($ in $\%): N_{\mathrm{CCN}}=N_{0} S_{\mathrm{w}}^{k}$, where $N_{0}$ and $k$ are the measured constants (Khain et al., 2000). The obtained aerosol size distribution is corrected in zones of very small and very large $\mathrm{CCN}$, that is, in size ranges where the Twomey formula is invalid. At $t>0$ the prognostic equation for the size distri- 
bution of non-activated $\mathrm{CCN}$ is solved. Using the value of $S$ calculated at each time step and at each grid point, the critical radius of $\mathrm{CCN}$ particles was determined according to the Köhler theory. The $\mathrm{CCN}$ with radii exceeding the critical value are activated, and new droplets are nucleated. The corresponding bins of the CCN size distributions become empty. In ST, this procedure is used at all cloud grid points.

In NA, droplet concentration at cloud base is calculated using the formula for $S_{\max }$ derived by Pinsky et al. (2012):

$S_{\max }=C w^{\frac{3}{4}} N_{\mathrm{d}}^{\frac{-1}{2}}$

where $w$ is vertical velocity at cloud base, $N_{\mathrm{d}}$ is droplet concentration, and coefficient $C$ slightly depends on the thermodynamical parameters only (see Table 1 for notations). A brief derivation of Eq. (1) is presented in Appendix A. Since the droplet concentration at cloud base is equal to the concentration of CCN activated at $S_{\mathrm{W}}=S_{\max }$, the droplet concentration at the cloud base can be calculated as

$$
N_{\mathrm{d}}=\int_{r_{n_{-} \text {cr }}\left(S_{\max }\right)}^{\infty} f\left(r_{n}\right) \mathrm{d} r_{n},
$$

where $f\left(r_{n}\right)$ is a size distribution of dry APs and $r_{n_{-} \text {cr }}$ is critical radius of $\mathrm{CCN}$ activated under $S_{\max }$. According to the Köhler theory, the critical radius relates to $S_{\max }$ as

$r_{n \_\mathrm{cr}}=\frac{A}{3}\left(\frac{4}{B S_{\max }^{2}}\right)^{\frac{1}{3}}$,

where coefficients $A$ and $B$ are the coefficients of the Köhler equation for equilibrium supersaturation (see Table 1 for notations). Substituting Eq. (2) into Eq. (1), one can obtain the following equation for $S_{\max }$ :

$$
S_{\max } \underbrace{\left[\int_{r_{n_{-} \mathrm{cr}}\left(S_{\max }\right)}^{\infty} f\left(r_{n}\right) \mathrm{d} r_{n}\right]^{\frac{1}{2}}}_{N_{\mathrm{d}}}=C w^{\frac{3}{4}} .
$$

Taking into account the relationship in Eq. (3), Eq. (4) contains only one unknown $S_{\max }$. This equation is easily solved by iteration calculating $S_{\max }, r_{n \_c r}\left(S_{\max }\right)$, and concentration of nucleated droplets at cloud base at each time step.

The values of $S_{\max }$ were calculated at all grid points corresponding to cloud base, which is determined as the first grid point from below, at which $S_{\mathrm{w}} \geq 0$.

\section{Design of simulations}

All simulations were performed within a computational domain of $153.9 \mathrm{~km} \times 19.2 \mathrm{~km}$, and a grid spacing of $300 \mathrm{~m}$ in the horizontal direction and $100 \mathrm{~m}$ in the vertical direction. Effects of NA on cloud microphysics were tested

\begin{tabular}{|c|c|c|}
\hline Symbol & Description & Units \\
\hline$A$ & $\frac{2 \sigma_{\mathrm{w}}}{\rho_{\mathrm{w}} R_{\mathrm{v}} T}$ & $\mathrm{~m}$ \\
\hline$A_{1}$ & $\frac{g}{R_{\mathrm{a}} T}\left(\frac{L_{\mathrm{W}} R_{\mathrm{a}}}{c_{p} R_{\mathrm{V}} T}-1\right)$ & $m^{-1}$ \\
\hline$A_{2}$ & $\frac{1}{q_{\mathrm{v}}}+\frac{L_{\mathrm{w}}^{2}}{c_{p} R_{\mathrm{v}} T^{2}}$ & - \\
\hline$B$ & $\frac{v_{n} \Phi_{s} \varepsilon_{m} M_{\mathrm{w}} \rho_{n}}{M_{n} \rho_{\mathrm{w}}}$ & - \\
\hline$B_{1}$ & $\frac{3}{F}\left(\frac{4 \pi \rho_{\mathrm{w}}}{3 \rho_{\mathrm{a}}}\right)^{\frac{2}{3}}$ & $\mathrm{~m}^{2} \mathrm{~s}$ \\
\hline$C_{1}$ & $1.058\left(\frac{F A_{1}}{3}\right)^{\frac{3}{4}}\left(\frac{3 \rho_{\mathrm{a}}}{4 \pi \rho_{\mathrm{w}} A_{2}}\right)^{\frac{1}{2}}$ & $m^{\frac{9}{4}} \mathrm{~s}^{\frac{-3}{4}}$ \\
\hline$c_{p}$ & $\begin{array}{l}\text { specific heat capacity of moist air at } \\
\text { constant pressure }\end{array}$ & $\mathrm{J} \mathrm{kg}^{-1} \mathrm{~K}^{-1}$ \\
\hline$D$ & $\begin{array}{l}\text { coefficient of water vapor diffusion } \\
\text { in the air }\end{array}$ & $\mathrm{m}^{2} \mathrm{~s}^{-1}$ \\
\hline$e$ & actual water vapor pressure & $\mathrm{Nm}^{-2}$ \\
\hline$e_{\mathrm{W}}$ & $\begin{array}{l}\text { saturation vapor pressure above the } \\
\text { flat surface of water }\end{array}$ & $\mathrm{Nm}^{-2}$ \\
\hline$g$ & acceleration of gravity & $\mathrm{ms}^{-2}$ \\
\hline$F$ & $\left(\frac{\rho_{\mathrm{w}} L_{\mathrm{w}}^{2}}{k_{\mathrm{a}} R_{\mathrm{v}} T^{2}}+\frac{\rho_{\mathrm{w}} R_{\mathrm{v}} T}{e_{\mathrm{w}}(T) D}\right)$ & $\mathrm{m}^{-2} \mathrm{~s}$ \\
\hline K & parameter of activity spectra & \\
\hline$k_{\mathrm{a}}$ & coefficient of air heat conductivity & $\mathrm{J} \mathrm{m}^{-1} \mathrm{~s}^{-1} \mathrm{~K}^{-1}$ \\
\hline$L_{\mathrm{W}}$ & latent heat for liquid water & $\mathrm{J} \mathrm{kg}^{-1}$ \\
\hline$M_{n}$ & molecular weight of aerosol salt & $\mathrm{kg} \mathrm{mol}^{-1}$ \\
\hline$M_{\mathrm{W}}$ & molecular weight of water & $\mathrm{kg} \mathrm{mol}^{-1}$ \\
\hline$N_{\mathrm{d}}$ & concentration of liquid droplets & $m^{-3}$ \\
\hline$N_{0}$ & parameter of activation spectra & \\
\hline$P$ & pressure of moist air & $\mathrm{Nm}^{-2}$ \\
\hline$q_{\mathrm{v}}$ & water vapor mixing ratio (air) & $\mathrm{kg} \mathrm{kg}^{-1}$ \\
\hline$q_{\mathrm{w}}$ & liquid water mixing ratio & $\mathrm{kg} \mathrm{kg}^{-1}$ \\
\hline$r_{\max }$ & drop radius at $z=z_{\max }$ & $\mathrm{m}$ \\
\hline$S_{\mathrm{W}}$ & $\begin{array}{l}S_{\mathrm{w}}=e / e_{\mathrm{W}}-1, \quad \text { supersaturation } \\
\text { over } \\
\text { water }\end{array}$ & - \\
\hline$S_{\max }$ & supersaturation maximum & - \\
\hline$T$ & absolute temperature & ${ }^{\circ} \mathrm{K}$ \\
\hline$T_{\mathrm{C}}$ & temperature at cloud base & ${ }^{\circ} \mathrm{C}$ \\
\hline$w$ & vertical velocity & $\mathrm{m} \mathrm{s}^{-1}$ \\
\hline$z$ & height over condensation level & $\mathrm{m}$ \\
\hline$z_{\max }$ & height of supersaturation maximum & $\mathrm{m}$ \\
\hline$\varepsilon_{m}$ & soluble fraction & - \\
\hline$\rho_{\mathrm{a}}$ & density of air & $\mathrm{kg} \mathrm{m}^{-3}$ \\
\hline$\rho_{N}$ & density of a dry aerosol particle & $\mathrm{kg} \mathrm{m}^{-3}$ \\
\hline$\rho_{\mathrm{W}}$ & density of liquid water & $\mathrm{kg} \mathrm{m}^{-3}$ \\
\hline$\sigma_{\mathrm{w}}$ & $\begin{array}{l}\text { surface tension of water-air } \\
\text { interface }\end{array}$ & $\mathrm{Nm}^{-1}$ \\
\hline$v_{n}$ & van't Hoff factor & - \\
\hline
\end{tabular}

Table 1. List of symbols.

in simulations of a thunderstorm observed in VillingenSchwenningen, southwest Germany, on 28 June 2006. Meteorological conditions (including sounding) of this storm are described by Khain et al. (2011). The background wind direction was quasi-2-D, which simplified the prescription of the background wind profile in the 2-D model. The wind speed increased with height from $\sim 10 \mathrm{~m} \mathrm{~s}^{-1}$ in the lower 
atmosphere to about $20 \mathrm{~m} \mathrm{~s}^{-1}$ at levels of $100-200 \mathrm{mb}$. Surface temperature was $22.9^{\circ} \mathrm{C}$, and the relative humidity near the ground was high $(\sim 85 \%)$, which led to a low lifting condensation level (LCL) of about $890 \mathrm{~m}$. The freezing level was located at around $3.5 \mathrm{~km}$. The observed maximum diameter of hailstones was about $5 \mathrm{~cm}$.

The convection was triggered by a cool pool, which is typical in simulations of long-lasting convection (Rotunno and Klemp, 1985).

Three sets of simulations were performed, each simulation in two versions: according to ST, where the critical CCN radius was calculated using a supersaturation calculated at the grid points using the values of temperature and humidity, and according to NA, where the critical CCN radius and $S_{\max }$ were determined from Eq. (4).

The first set of simulations aims at the comparison of the microphysics between NA and ST in cases of high $\left(N_{0}=\right.$ $\left.3500 \mathrm{~cm}^{-3}\right)$ and low $\left(N_{0}=100 \mathrm{~cm}^{-3}\right) \mathrm{CCN}$ concentrations. Minimum CCN radii were set equal to 0.015 and $0.0125 \mu \mathrm{m}$, respectively. These values correspond to the data according to which the nuclei mode (the smallest $\mathrm{CCN}$ ) in marine aerosol size distribution contains aerosols smaller than the nuclei mode in continental cases or even than in urban cases (Ghan et al., 2011). Similar CCN size distributions were used by Khain et al. (2011). These simulations are referred to as E3500 and E100 (ST) and EN3500 and EN100 (NA), respectively.

In the second set of simulations the smallest $\mathrm{CCN}$ were added into the AP spectra. The large impact of the smallest $\mathrm{CCN}$ in formation of ice crystals in cloud anvils was shown by Khain et al. (2012). The minimum $\mathrm{CCN}$ radii were taken equal to 0.006 and $0.003 \mu \mathrm{m}$ in cases of high and low CCN concentrations, respectively. These simulations are referred to as E3500-S, EN3500-S, E100-S, and EN100-S, where the symbol S denotes small APs.

In the first and the second sets of simulations the slope parameter $k$ was assumed equal to 0.9 .

The third set of simulations was similar to the second one but with the slope parameter $k=0.5$. In many studies investigating effects of aerosols on cloud microphysics, only parameter $N_{0}$ is changed. However, the slope parameter determines the relationship between concentration of smaller and larger CCN, so concentration of nucleated droplets also depends on the slope parameter. The simulations of the third set are referred to as E3500-S-05, EN3500-S-05, E100-S-05, and EN100-S-05. Size distributions of CCN in the simulations are shown in Fig. 1.

$\mathrm{CCN}$ concentrations in the simulations $s$ are presented in Table 2. Although the difference between the total aerosol concentrations in the cases of $k=0.5$ and 0.9 is not large, in the case of $k=0.5$ the $\mathrm{CCN}$ size distribution contains more large $\mathrm{CCN}$ and fewer small CCN. These size distributions were assumed within the lower $2 \mathrm{~km}$ layer. Above this level, the $\mathrm{CCN}$ concentration in each mass bin was decreased ex-

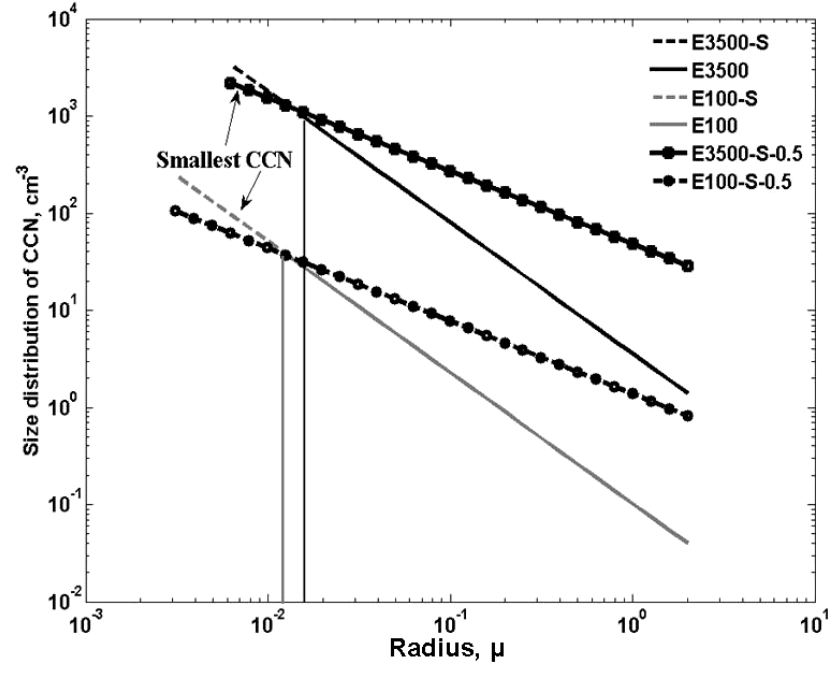

Figure 1. The initial size distributions of aerosols near the surface in different simulations.

ponentially with height. Above $8 \mathrm{~km}$, the $\mathrm{CCN}$ concentration was set constant.

\section{Results of simulations}

\subsection{Vertical profiles of supersaturation near cloud base}

The model calculates supersaturation at the model grid points which typically do not exactly coincide with the cloud base level where supersaturation $S_{\mathrm{w}}=0$. We consider the first level where $S_{\mathrm{w}} \geq 0$ as the cloud base. Since the supersaturation maximum is reached not far from the cloud base level, especially for high-AP-concentration cases (Pinsky et al., 2012), we attribute the values of $S_{\max }$ to this level. Correspondingly, the difference between the droplet concentrations in NA and ST is also attributed to this level. Figure 2 shows vertical profiles of supersaturation calculated in ST and NA simulations in the atmospheric columns where the velocity at cloud base was equal to $1 \mathrm{~m} \mathrm{~s}^{-1}$. It is natural that the values of $S_{\max }$ are larger in the case of low CCN concentration as compared to the case of high $\mathrm{CCN}$ concentration. For purposes of the present study, a more interesting finding is that the values of $S_{\max }$ calculated using NA are substantially larger than $S_{\mathrm{w}}$ calculated at model level associated with the cloud base in ST. The difference between NA and ST in the supersaturation values leads to a substantial difference in the droplet concentrations, especially in cases of high CCN concentration. Calculation of $S_{\max }$ at cloud base changes the vertical profile of supersaturation above it. While in ST supersaturation changes only slightly or even increases with height within 100-200 m above cloud base, in the NA supersaturation decreases within this layer above the supersaturation maximum in agreement with the theory (Rogers and Yau, 1989; Pinsky et al., 2012, 2013). 
Table 2. $\mathrm{CCN}$ concentrations in different experiments in the boundary layer.

\begin{tabular}{lrr|rr}
\hline & \multicolumn{2}{c|}{ High CCN concentration, $\mathrm{cm}^{-3}$} & \multicolumn{2}{c}{ Low CCN concentration, $\mathrm{cm}^{-3}$} \\
\cline { 2 - 5 } Slope parameter & No smallest CCN & With smallest CCN & No smallest CCN & With smallest CCN \\
\hline$k=0.9$ & 840 & 2930 & 33 & 214 \\
$k=0.5$ & 1552 & 3140 & 53 & 152 \\
\hline
\end{tabular}

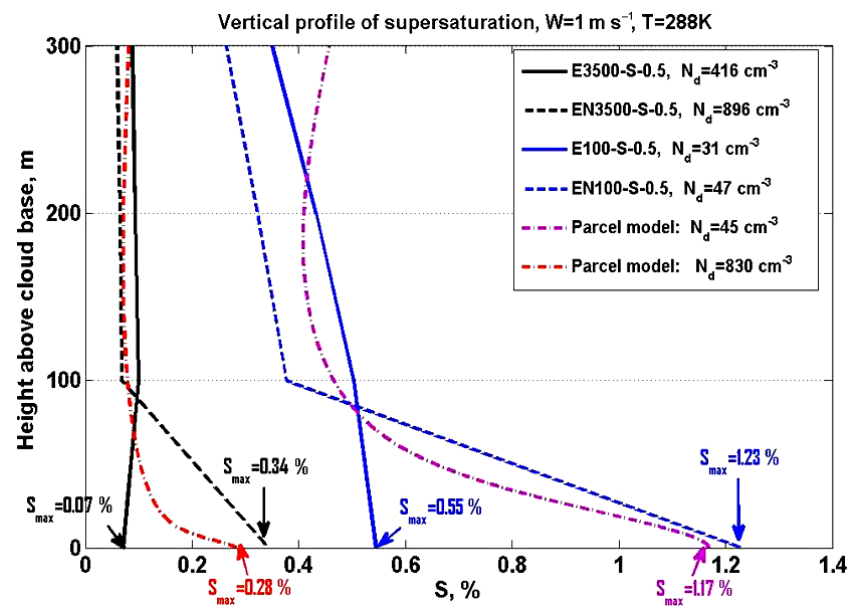

Figure 2. Examples of vertical profiles of the supersaturation above cloud base calculated using HUCM and a benchmark parcel model. The columns with $w$ close to $1 \mathrm{~m} \mathrm{~s}^{-1}$ at cloud base were chosen for comparison. The values of $S_{\max }$ in HUCM were calculated according to Pinsky et al. (2012). The values of droplets concentration calculated at cloud base in different simulations are shown as well (see legend box).

To justify the values of supersaturation and droplet concentration obtained in NA, benchmark simulations using a parcel model were performed. The parcel model describes APs and drops using drop size distribution defined on a mass grid containing 2000 mass bins (Pinsky and Khain, 2002). It calculates growth of APs and droplets by solving the equation for diffusional growth written in the most general form without using parameterization of droplet nucleation. The time step used for solving the diffusional growth equation was $0.001 \mathrm{~s}$. The model was used earlier for developing lookup tables relating parameters of APs and vertical velocity to droplet concentration (Segal and Khain, 2006). Simulations with the parcel model were performed for the same vertical velocity at cloud base, temperature, and $\mathrm{CCN}$ distributions as in the HUCM simulations. As can be seen from Fig. 2, the values of supersaturation and droplet concentration calculated using NA are much closer to those calculated using the parcel model than the values calculated using ST.

The model level associated with the cloud base (where $S_{\mathrm{w}} \geq 0$ ) is slightly higher than the LCL, where $S_{\mathrm{w}}=0$. At the same time, the calculations performed according to Pinsky et al. (2012) show that the level where $S_{\mathrm{w}}=S_{\max }$ is lo- cated from about $20 \mathrm{~m}$ (for high CCN concentration) to about $60 \mathrm{~m}$ (for low CCM concentration) higher than the LCL. The estimations show, therefore, that the level where $S_{\mathrm{w}}=S_{\max }$ is quite close to the model cloud base level. Accordingly, the droplet concentration determined at $S_{\mathrm{w}}=S_{\mathrm{max}}$ is assigned to the corresponding grid point at the model cloud base.

\subsection{High CCN concentration}

In this section we compare the results for three pairs of simulations of clouds that were developed in a highly polluted atmosphere. Figure 3 shows the fields of droplet concentration $N_{\mathrm{d}}$ at the developing stage of the cloud evolution in E3500-S0.5 (a), EN3500-S-0.5 (b), E3500-S (c), and EN3500-S (d). The maximum $N_{\mathrm{d}}$ in NA is reached at cloud base, which makes the cloud base well pronounced. The difference between droplet concentrations in ST and NA experiments decreases with height. The highest droplet concentration is reached in simulations where the $\mathrm{CCN}$ activation spectrum was characterized by the slope parameter $k=0.5$. This can be attributed to the fact that at $k=0.5$ the aerosol spectrum contains more $\mathrm{CCN}$ which are activated at cloud base than at $k=0.9$.

Vertical profiles of the maximum values of droplet concentration and of cloud water content (CWC) averaged over time periods of storm development (panels a and b) and over the mature stage (panels $\mathrm{c}$ and d) are presented in Fig. 4.

In NA the $N_{\mathrm{d}}$ maximum is reached near cloud base, and the droplet concentration decreases with height. This behavior of $N_{\mathrm{d}}(z)$ is more realistic than in ST, where $N_{\mathrm{d}}$ increases with height up to an altitudes $2-4 \mathrm{~km}$, depending on the stage of storm evolution. This increase in the $N_{\mathrm{d}}$ in ST is caused by in-cloud activation of mid-size $\mathrm{CCN}$ which were not activated at cloud base in the standard approach. In NA, these $\mathrm{CCN}$ were activated at cloud base. There is, therefore, a negative feedback in the supersaturation-droplet concentration relationship: an underestimation of supersaturation at low levels in the ST simulations leads to the underestimation of droplet concentration and to the corresponding increase in supersaturation at comparatively small distances above cloud base. These results indicate that, in models where droplet nucleation is calculated only at cloud base, the correct calculation of $S_{\max }$ at cloud base is strictly necessary to obtain reasonable values of $N_{\mathrm{d}}$ in clouds. 

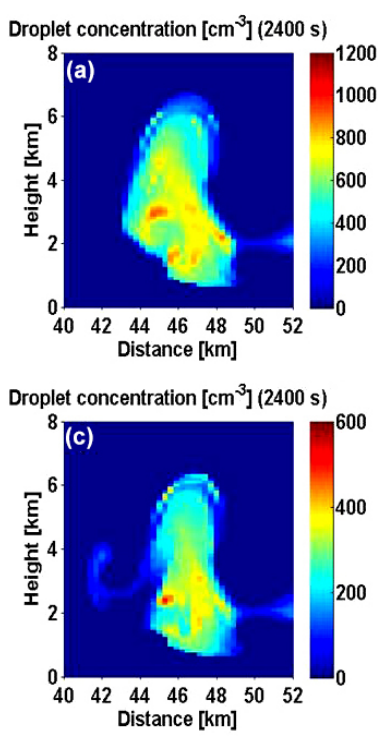
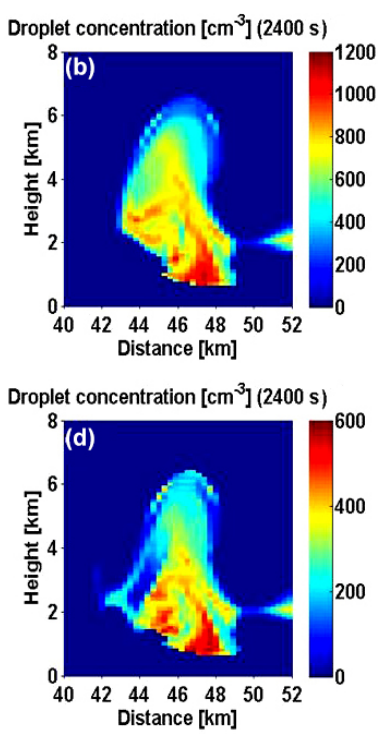

Figure 3. Field of droplet concentration at $t=2400 \mathrm{~s}$ in (a) E3500S-0.5, (b) EN3500-S-0.5, (c) E3500-S, and (d) EN3500-S.

At a height of about $4-5 \mathrm{~km}$, droplet concentrations in ST and NA become nearly the same. Figure $4 \mathrm{a}$ and $\mathrm{c}$ also show that $N_{\mathrm{d}}$ is very sensitive to the slope parameter of the CCN activation spectrum. The maximum $N_{\mathrm{d}}$ reached at cloud base is about $1100 \mathrm{~cm}^{-3}$ in EN3500-S-05 $(k=0.5)$ as compared to $\sim 550 \mathrm{~cm}^{-3}$ in EN3500-S $(k=0.9)$. This difference is caused by the fact that in the case of $k=0.5$ the concentration of CCN with sizes exceeding $\sim 0.015 \mu \mathrm{m}$ (which are activated at cloud base) is larger than in the case of $k=0.9$ (see Fig. 1).

The effect of the smallest $\mathrm{CCN}$ on $N_{\mathrm{d}}$ (and on entire ice microphysical structure) becomes very important above $6 \mathrm{~km}$. In simulations containing the smallest $\mathrm{CCN}$, these $\mathrm{CCN}$ are activated, producing new small droplets at heights of around $6.5-8 \mathrm{~km}$. The increase in $N_{\mathrm{d}}$ is shown in Fig. $4 \mathrm{a}$ and $\mathrm{c}$ by red arrows. These smallest $\mathrm{CCN}$ are not activated at cloud base even in NA (where $S_{\max }$ is larger than $S_{\mathrm{w}}$ in ST). This in-cloud nucleation is caused by an increase in supersaturation at these levels due to a decrease in CWC (Fig. 4b, d) and an increase in vertical velocity (not shown). The increase in $N_{\mathrm{d}}$ by activation at high levels and its effect on concentration of ice crystals in cloud anvils of deep convective clouds were also reported by Khain et al. (2012).

Since the slope parameter determines concentration both of larger $\mathrm{CCN}$ and of the smallest $\mathrm{CCN}$, the slope parameter also affects the concentration of droplets nucleated at high levels.

Vertical profiles of CWC (Fig. 4b, d) are typical of deep convective clouds developing in the highly polluted environment: CWC is large and has its maximum at about $5 \mathrm{~km}$, i.e., at quite high altitude.
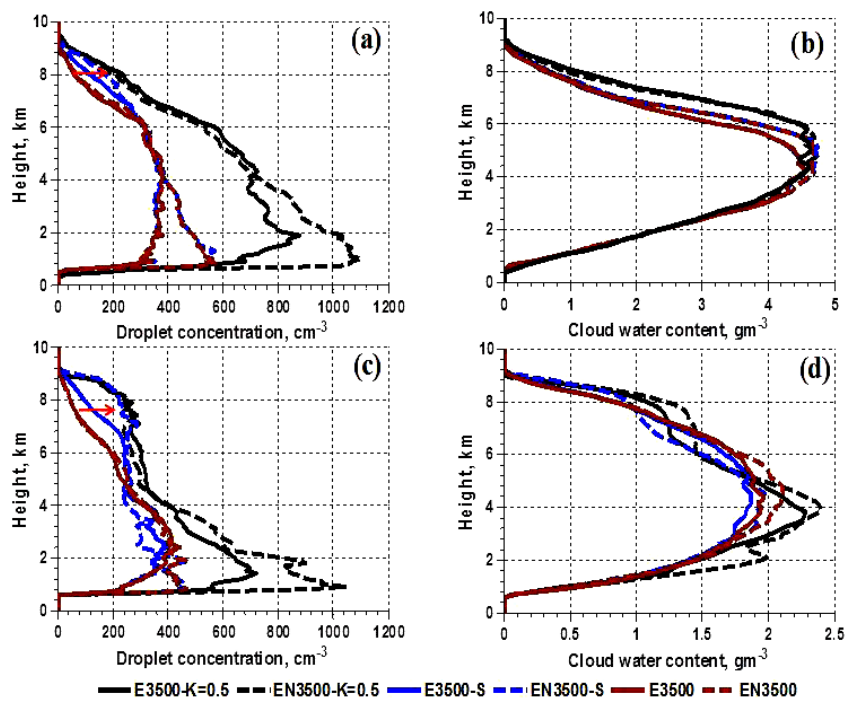

Figure 4. Vertical profiles of the maximum values of droplet concentration (a, d) and CWC (b, d) in simulations with high CCN concentration. The profiles are obtained by averaging over the time period of 2400-3000 s (upper row) and over the time period of 4860$5460 \mathrm{~s}$ (bottom row). Panel (c) shows a zoom of panel (b) for large CWC.

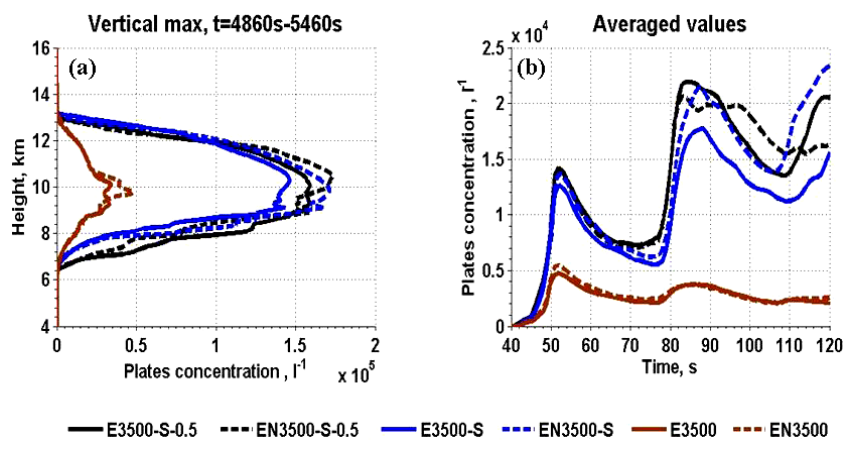

Figure 5. Vertical profiles of (a) maximum values of plate concentration and (b) time dependencies of averaged plate concentration. The profiles are obtained by averaging over the time period of 4860 $5460 \mathrm{~s}$. The low and the upper arrows in panel (b) show approximate contribution of the smallest $\mathrm{CCN}$ and the additional $\mathrm{CCN}$ activated in NA, respectively.

Figure 5a shows the vertical profiles of maximum concentration of plate crystals (in HUCM homogeneous freezing leads to formation of plates) averaged over the mature stage of cloud evolution (from 4860 to $5460 \mathrm{~s}$ ). The number concentration of ice crystals in E3500 and EN3500 (in which there are no smallest $\mathrm{CCN}$ in the initial $\mathrm{CCN}$ spectrum) is a factor of 5 lower than in simulations with the CCN spectra containing the smallest $\mathrm{CCN}$. The results show that ice crystal concentration in NA is higher only slightly than in ST. Thus the concentration of ice crystals in cloud anvils is determined to a large extent by the concentration of the 

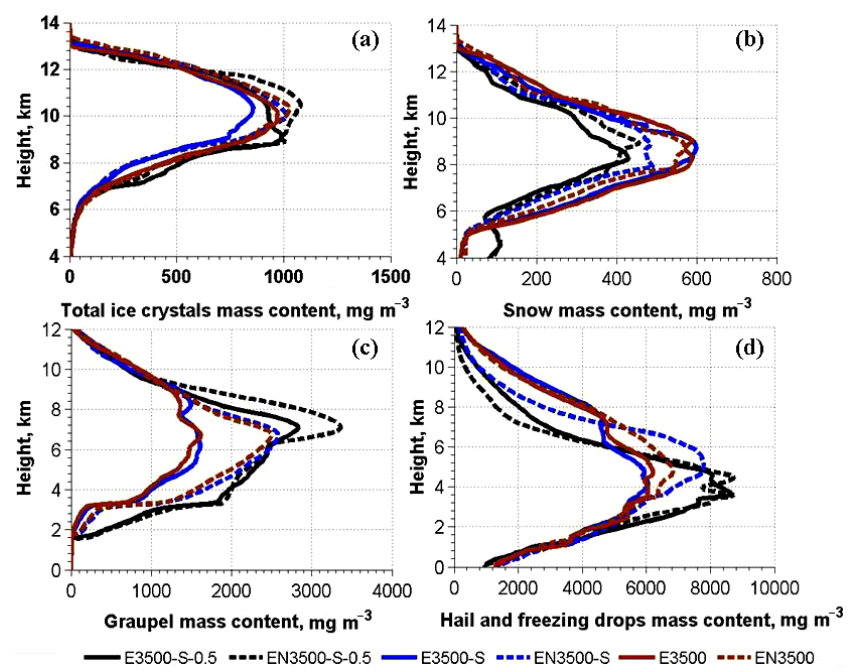

Figure 6. Vertical profiles of the maximum values of mass content: (a) total ice crystals, (b) snow, (c) graupel, and (d) total hail and freezing drops in simulations with high $\mathrm{CCN}$ concentration. The profiles are obtained by averaging over the time period of 4860 $5460 \mathrm{~s}$.

smallest CCN in the CCN spectra and is substantially less sensitive to larger CCN, which are activated at cloud base. Figure $5 \mathrm{~b}$ shows that this conclusion is valid for the entire period of the simulation. In agreement with Fig. 4c, the concentration of plates increased when NA was used (Fig. 5b). The comparative contribution of the smallest $\mathrm{CCN}$ and $\mathrm{CCN}$ additionally activated at the cloud base in NA (as compared to ST) is shown in Fig. 5 b by arrows.

Figure 6 shows the vertical profiles of time-averaged maximum mass contents of ice crystals, snow, graupel, and hail + freezing drops at the storm mature stage. The maximum difference between ice crystal mass contents takes place at $\sim 10-11 \mathrm{~km}$, where ice crystals are caused by homogeneous freezing.

The most pronounced effect of NA is an increase in the accretion rate. In agreement with results of simulations of aerosol effects on ice microstructure of deep convective clouds (Khain, 2009; Tao et al., 2012; Khain et al., 2016), the intensification of riming leads to a decrease in the snow mass content and to an increase in the mass contents of graupel (Fig. 6b, c). The existence of the smallest CCN concentration leads to further decrease in the snow mass content and to an increase in the graupel mass content. The smallest $\mathrm{CCN}$ lead to higher supercooled droplet concentration and to an increase in the liquid mass available for riming (Fig. 4d, e).

\subsection{Low CCN concentration}

In this section we compare the results for three pairs of simulations in which clouds were developed in the atmosphere with low CCN concentration: (a) E100 and EN100, (b) E100-
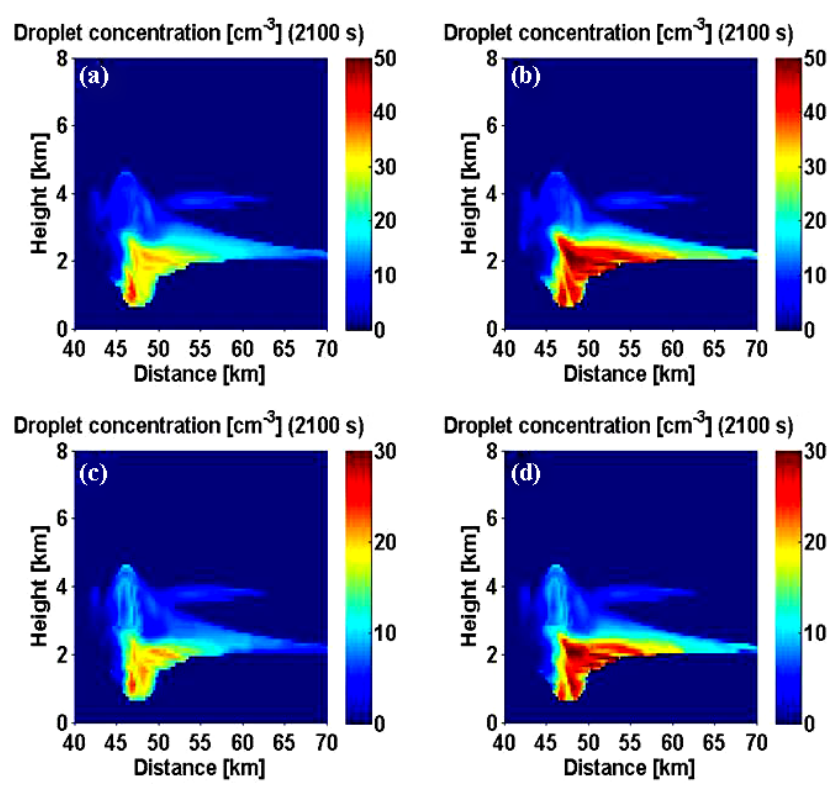

Figure 7. Fields of droplet concentration at $t=2100 \mathrm{~s}$ in (a) E100S-0.5, (b) EN100-S-0.5, (c) E100-S, and (d) EN100-S simulations.

S and EN100-S, and (c) E100-S-0.5 and EN100-S-0.5. After the first $35 \mathrm{~min}$ of cloud evolution, the cloud base is located at $700-800 \mathrm{~m}$ altitude, and $T=16.8^{\circ} \mathrm{C}$ at this level.

The fields of droplet concentration $N_{\mathrm{d}}$ in different simulations at the developing stage of the cloud evolution are shown in Fig. 7. The maximum $N_{\mathrm{d}}$ in a NA is reached at cloud base, which makes the cloud base well pronounced. The difference in droplet concentrations between ST and NA simulations decreases with height. Although the difference in $N_{\mathrm{d}}$ between NA and ST is very pronounced, the absolute difference is not large (about $20 \mathrm{~cm}^{-3}$ ). This low $N_{\mathrm{d}}$ determines a typical maritime microphysical structure of clouds in both NA and ST cases.

Figure 8 shows vertical profiles of the maximum values of droplet concentration and CWC averaged over the time period of 3420-4020 s (mature stage). One can see a dramatic difference in the profiles of droplet concentration and between CWC values at low $\mathrm{CCN}$ concentration as compared to high $\mathrm{CCN}$ concentration (Fig. 4). At low CCN concentration, droplet collisions are efficient and droplet concentration decreases with height much faster than in polluted air. As a result, the CWC maximum at low $\mathrm{CCN}$ concentration is located at a height of $2 \mathrm{~km}$ as compared to $5 \mathrm{~km}$ in the case of high $\mathrm{CCN}$ concentration. These differences determine the huge difference in the ice microphysics.

Figure 8 shows that both the droplet concentration and CWC are larger in NA than ST. The main differences between droplet concentrations near cloud base are, however, determined by the difference in the slope parameter value: at $k=0.5$ there are more $\mathrm{CCN}$ of sizes exceeding $0.015 \mu \mathrm{m}$ than at $k=0.9$ (Fig. 1). These $\mathrm{CCN}$ are activated at cloud 

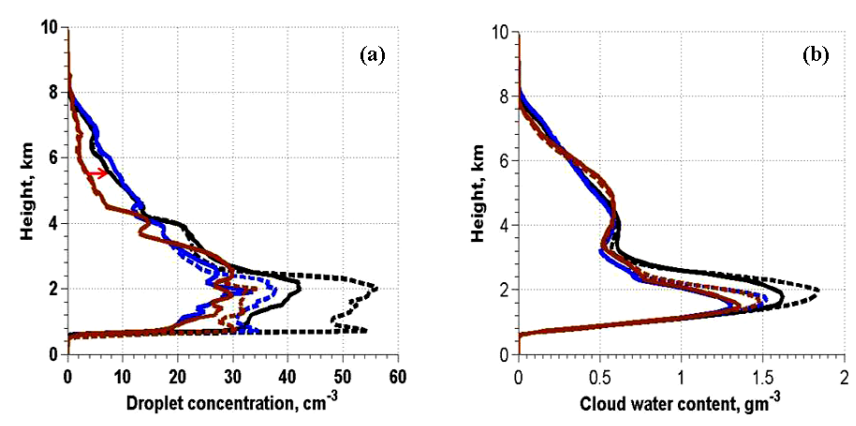

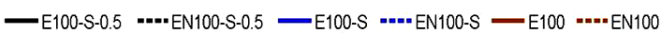

Figure 8. Vertical profiles of the maximum values of droplet concentration (a) and CWC (b) in simulations with low CCN concentration $\left(N_{0}=100 \mathrm{~cm}^{-3}\right)$. The profiles are obtained by averaging over the time period of $3420-4020$ s. The red arrow shows the increase in droplet concentration due to in-cloud nucleation in simulations with the $\mathrm{CCN}$ spectra containing small $\mathrm{CCN}$.

base, leading to higher concentration in simulations with $k=0.5$, especially when NA is applied.

Efficient collisions (seen by the sharp decrease in the CWC above $z=2 \mathrm{~km}$ ) and rainfall decrease the droplet concentration. As a result, the supersaturation increases and leads to in-cloud nucleation and an increase in the droplet concentration already at distances of a few hundred meters above the cloud base. However, since the concentration of $\mathrm{CCN}$ is low, the amount of new nucleated droplets in the simulations was only about $5-10 \mathrm{~cm}^{-3}$. The second layer of intense incloud nucleation caused by activation of the smallest $\mathrm{CCN}$ is seen within the altitude layer from 4 to $8 \mathrm{~km}$. The difference in droplet concentration within this layer is fully related to the existence/absence of the smallest $\mathrm{CCN}$ in the $\mathrm{CCN}$ size spectrum. The differences between droplet concentration in ST and NA simulations are not significant at these levels.

This result agrees with the case of high CCN concentration when droplet concentration at higher levels is to a large extent determined by the smallest $\mathrm{CCN}$ in the droplet spectrum.

Figure 9 presents the vertical profiles of maximum mass contents of ice crystals, snow, graupel, and hail + freezing drops at the mature stage of cloud evolution. Comparison with Fig. 6 shows that, with the exception of snow, the mass contents of different ice hydrometeors at low CCN concentration are substantially lower than at high CCN concentration. The main reason for such a difference is lower CWC at low $\mathrm{CCN}$ concentration, which leads to less intense riming and, consequently, to slow growth of ice particles.

Figure 9 shows that the profiles of ice hydrometeors in NA and ST are similar. It means that the ice microphysics is to a large extent determined by the mass of supercooled droplets at high levels, which in turn is determined by the smallest $\mathrm{CCN}$ in the CCN size spectrum. The effects of the smallest $\mathrm{CCN}$ and the shape of $\mathrm{CCN}$ size spectra on droplet concen-
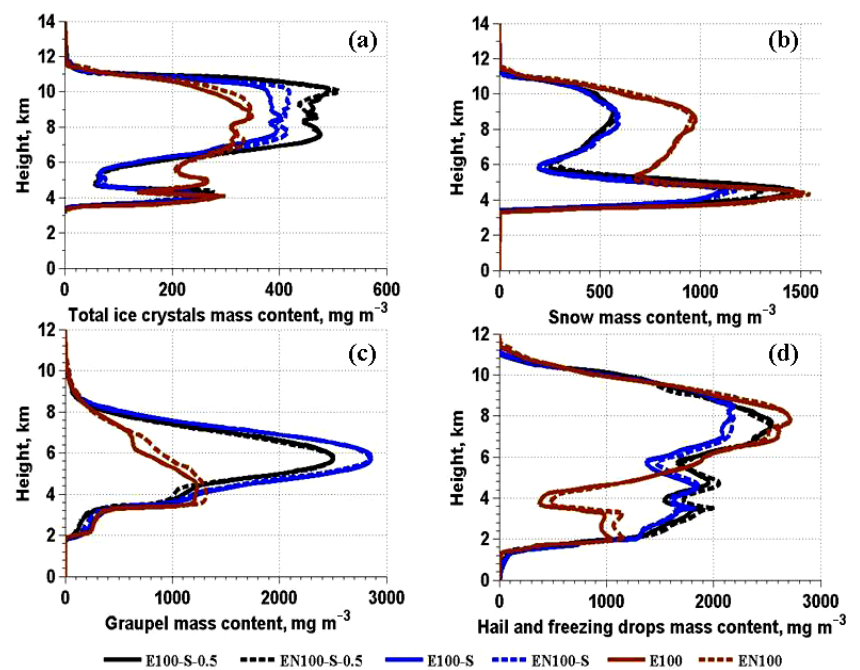

Figure 9. Vertical profiles of the maximum values of mass content: (a) total ice crystals, (b) snow, (c) graupel, and (d) total hail and freezing drops in the simulations with low $\mathrm{CCN}$ concentration. The profiles are obtained by averaging over the time period of 3420 4020 s.

tration and the concentration on ice microphysics are much stronger than the effect of additional droplets nucleating at cloud base in NA. The reason for this effect was explained above.

The increase in the concentration of the smallest $\mathrm{CCN}$ and in droplet concentration leads to an increase in the ice crystals' mass content occurring at about the level of homogeneous freezing (Fig. 9a).

The mass content of snow decreases with the increase in the smallest $\mathrm{CCN}$ concentration, because intensification of riming of snow leads to its conversion to graupel (Fig. 9b). Consequently, the graupel mass content increases (Fig. 9c). With regard to mass content of hail, the increase in the smallest CCN concentration leads to a decrease in the hail content above $6 \mathrm{~km}$ and to its increase below this level (Fig. 9d). The higher hail mass content above $6 \mathrm{~km}$ layer in the absence of the smallest $\mathrm{CCN}$ is likely related to the fact that the low droplet concentration leads to formation of raindrops in high concentration. Although these raindrops are of comparatively small size, the total raindrop mass content is larger than that in the case of higher drop concentration. These raindrops rapidly freeze above the freezing level, producing hail (actually frozen drops) with total mass larger than at high $\mathrm{CCN}$ concentration. This effect is discussed by Ilotoviz et al. (2016) in detail. In HUCM, frozen raindrops are assigned to the hail category due to their high density. When hail is defined as particles with sizes exceeding $1 \mathrm{~cm}$, the amount of hail at low $\mathrm{CCN}$ concentration is negligible.

Higher hail mass content below $6 \mathrm{~km}$ in the presence of the smallest $\mathrm{CCN}$ can be attributed to intense conversion of heavy rimed graupel to hail, as well as to more efficient hail 
growth by riming. Note that sizes of hail particles forming in a deep convective cloud developing in the polluted atmosphere are larger than hail forming in a cloud developing in clean air (Ilotoviz et al., 2016). Due to larger size, hail in the polluted case falls to the surface (Fig. 6d), while in clean air hail melts at $1.5 \mathrm{~km}$ in the absence of small $\mathrm{CCN}$ and in the vicinity of the surface if the $\mathrm{CCN}$ size spectrum contains the smallest CCN.

\subsection{The impact on precipitation}

Figure 10a shows the accumulated rain at the surface in the polluted air. Accumulated rain is maximum in EN3500-S0.5 , where the effect of the smallest $\mathrm{CCN}$ is combined with the effect of a comparatively large amount of large CCN. This synergetic effect of the smallest and large CCN is described by Khain et al. (2011). In most simulations, the masses of accumulated rain are quite similar.

Comparison of Fig. 10a and b shows that the accumulated rain at low aerosol concentration is lower than at high $\mathrm{CCN}$ concentration, which is in agreement with many previous studies. Accumulated rain in NA was found to be quite close to that in ST. The main difference in the values of accumulated rain at low CCN concentration is caused by effects of the smallest aerosols increasing the mass of precipitating ice particles.

The amount of hail at the surface in polluted air (Fig. 10c) is substantially larger than in clean air (Fig. 10d) due to lower sizes and faster melting of hail particles when CCN concentration is low. The effect of APs on the size and amount of hail at the surface was investigated by Ilotoviz et al. (2016) in detail.

The amount of hail at the surface in polluted air is slightly higher in EN3500-S-0.5 than E3500-S-0.5 (Fig. 10c). We attribute this effect to a higher rate 0 of riming in EN3500S-0.5 due to a higher amount of supercoold water (Fig. 4b, d). There are no significant differences in the other cases of polluted air.

The main factor determining the differences in the amount of hail falling to the surface at low $\mathrm{CCN}$ concentration is the effect of the smallest CCN. The increase in concentration of the smallest CCN leads to an increase in hail growth by riming.

With regard to the ratio of hail amounts in the experiments with the smallest APs, sooner or later intensification of convective cells (which is more or less random) may affect the ratio. Since the mass of hail falling to the surface in clean air is very low, a larger computational area is required to obtain reliable statistics.

\section{Conclusions}

Sensitivity of the microphysics of deep convective clouds to the concentration of aerosols and to the shape of aerosol size
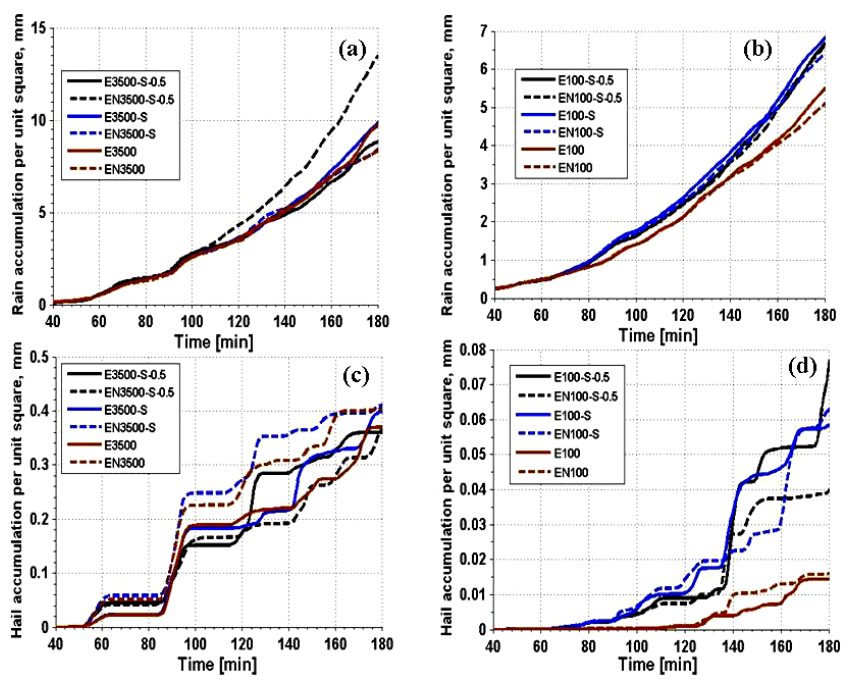

Figure 10. Time dependencies of accumulated rain at the surface for polluted (a) and for clean(b) air. Accumulated hail at the surface for polluted (c) and for clean (d) air in different simulations in polluted cases.

distribution is investigated using a new version of a 2-D spectral (bin) microphysics cloud model (HUCM). A new component of the model is the calculation of maximum supersaturation at cloud base using the analytical expression derived by Pinsky et al. (2012). The cloud microphysical structure obtained using this expression is compared with that obtained with supersaturation calculated at model grid points.

The goal of the study was twofold: (a) to test the effects of the improved calculation of supersaturation maximum near cloud base (new approach vs. standard approach) at different aerosol loadings and (b) to evaluate sensitivity of cloud microphysics to concentration and shape of size distribution of aerosol particles. In the simulations, shape of CCN size distributions was changed by changing the value of the slope parameter in the expression for activation spectrum (the values of $k=0.5$ and $k=0.9$ were used) and by adding the smallest $\mathrm{CCN}$ with radii below $0.015 \mu \mathrm{m}$.

The values of $S_{\max }$ near cloud base calculated by the theoretical analysis were found to be substantially larger than the supersaturation values calculated explicitly at model grid points associated with cloud base. The comparison of the values of supersaturation at cloud base and droplet concentration in the model simulations with the corresponding values calculated using a benchmark parcel model showed that NA simulates cloud base supersaturation and droplet concentration much more accurately than ST. Thus, the first main conclusion of the study is that the droplet concentration field in NA is substantially more realistic than in ST, with the maximum of droplet concentration in NA located near cloud base in agreement with classical results (Rogers and Yau, 1996). The increased droplet concentration makes the cloud base more pronounced. The improvement of the representation of 
the vertical profile of the droplet concentration is especially significant in the case of high CCN concentration, where utilization of $S_{\max }$ leads to a substantial increase in the concentration of droplets near cloud base. Thus, even at $100 \mathrm{~m}$ vertical resolution, it is necessary to use analytical expressions for $S_{\max }$. At low CCN concentration, the improved representation of droplet concentration above cloud base has a comparatively weak effect on cloud microphysics. This result can be attributed to the fact that droplet concentration increases relatively slightly if it is more accurately calculated since the available CCN concentration is low. As a result, intense warm rain rapidly arises in both NA and ST.

The error in calculation of droplet concentration near cloud base in ST is compensated to a significant extent by in-cloud nucleation above cloud base. Indeed, in NA droplet concentration increases with height up to a level of $4 \mathrm{~km}$ (Fig. 4a). The only reason for such an increase is the in-cloud nucleation of comparatively large $\mathrm{CCN}$.

Models with microphysical schemes that do not describe in-cloud droplet nucleation should include calculation of $S_{\max }$ at cloud base to avoid large errors in simulation of the microphysical cloud structure.

The second main conclusion is the high importance of the shape of CCN size distribution. Cloud microphysics was found to be highly sensitive to the slope parameter of the $\mathrm{CCN}$ activation spectra. The effect is comparable with the change in the total $\mathrm{CCN}$ concentration by the change in the intercept parameter $N_{0}$. The utilization of $k=0.5$ instead of $k=0.9$ nearly doubled droplet concentration near cloud base, leading to corresponding effects on cloud microphysics, in particular, to an increase in accumulated rain.

The third main conclusion is the high sensitivity of ice microphysics to the existence of the smallest $\mathrm{CCN}$ in the $\mathrm{CCN}$ size spectrum. Both in cases of low and high $\mathrm{CCN}$ concentration, the differences in ice microphysics are determined to a large extent by concentration of the smallest aerosols in the $C C N$ spectra. In cases of high CCN concentration, the effect of the smallest CCN in NA becomes important above $5-6 \mathrm{~km}$ altitude, where they are activated, producing additional supercooled liquid droplets. The latter leads to the increase in the concentration of ice crystals above the level of homogeneous freezing by factor of about 5 , to doubling of graupel mass maximum. The smallest $\mathrm{CCN}$ also influence hail size and mass content.
In the case of low $\mathrm{CCN}$ concentration the smallest $\mathrm{CCN}$ also lead to an increase in the concentration and mass contents of ice crystals and to a significant increase of graupel and hail mass contents. Note that many probes of CCN measure concentration of $\mathrm{CCN}$ at supersaturations not exceeding $0.6 \%$. In this case the concentration of the smallest CCN which remain non-activated at this supersaturation remains unknown. Such measurements do not provide necessary information for investigation of mixed-phase and ice microphysics.

Accumulated rain amount in the case of high $\mathrm{CCN}$ concentration turned out to be higher than in the case of low CCN concentration. This result was discussed by Khain (2009) and Ilotoviz et al. (2016), showing that formation of hail increases precipitation efficiency of midlatitude storms.

Ice precipitation (calculated in millimeters of melted hail) at the surface is much lower than liquid precipitation. Nevertheless, hail precipitation at the surface in the case of high $\mathrm{CCN}$ concentration is higher than in the case of low CCN concentration by an order of magnitude, in agreement with results by Khain et al. (2011) and Ilotoviz et al. (2016). This effect can be attributed by formation of larger hail particles in the case of high CCN concentration (high supercooled mass content). The large hail particles reach the surface, while smaller hail forming in the case of low $\mathrm{CCN}$ concentration melts without reaching the surface.

The concentrations of drops and ice crystals are important parameters determining cloud radiative properties. In this context, more accurate calculation of the concentrations using NA as well as taking into account the effects of the smallest CCN should improve the accuracy of evaluation of radiative cloud properties. The proposed approach of calculation of nucleation of droplets at cloud base is simple in the utilization and computationally efficient. It can be used in cloud-resolved models with different vertical grid spacing. The utilization of cruder vertical model resolution may lead to larger errors in cases when droplet concentration at cloud base is calculated using supersaturations calculated at model grid points.

\section{Data availability}

Numerical codes of the model are available upon request. 


\section{Appendix A: Derivation of an expression for the supersaturation maximum at cloud base}

Detailed description of the derivation of Eq. (1) is given in Pinsky et al. (2012). Below we present only a short description. Assuming that near cloud base $S_{\mathrm{w}} \ll 1$, the equation for supersaturation can be written as

$\frac{\mathrm{d} S_{\mathrm{w}}}{\mathrm{d} t}=A_{1} \frac{\mathrm{d} z}{\mathrm{~d} t}-A_{2} \frac{\mathrm{d} q_{\mathrm{w}}}{\mathrm{d} t}$

where coefficients $A_{1}$ and $A_{2}$ are presented in Table $1, z$ is the height above cloud base, and $q_{\mathrm{w}}$ is liquid water mixing ratio. The first term on the right-hand side of Eq. (A1) describes an increase in supersaturation due to adiabatic air cooling during ascent, whereas the second term describes the supersaturation decrease caused by condensation of water vapor on droplets. Integration of Eq. (A1) leads to the equation of mass balance:

$S_{\mathrm{w}}=A_{1} z-A_{2} q_{\mathrm{w}}+C_{1}$,

where $C_{1}=0$ at cloud base. Assuming monodisperse droplet size distributions with droplets of radii $r$, the liquid water mixing ratio can be written as

$q_{\mathrm{w}}=\frac{4}{3} \pi \frac{\rho_{\mathrm{w}}}{\rho_{\mathrm{a}}} N_{\mathrm{d}} r^{3}$ where $N_{\mathrm{d}}$ is the droplet concentration. The equation for diffusional growth can be written in a form where the curvature term and the chemical term are omitted (Pinsky et al., 2012):

$\frac{\mathrm{d} r}{\mathrm{~d} t}=\frac{1}{F r} S_{\mathrm{w}}$

The expression for coefficient $F$ is presented in Table 1. Coefficients $A_{1}, A_{2}$, and $F$ slightly depend on temperature and can be assumed constant in the analysis. Using Eqs. (A2) (A4), Eq. (A1) can be rewritten in the closed form as

$\frac{\mathrm{d} S_{\mathrm{w}}}{\mathrm{d} z}=A_{1}-\frac{1}{w} B_{1}\left(A_{2} N_{\mathrm{d}}\right)^{\frac{2}{3}}\left(A_{1} z-S_{\mathrm{W}}\right)^{\frac{1}{3}} S_{\mathrm{w}}$,

where $B_{1}=\frac{3}{F}\left(\frac{4 \pi}{3} \frac{\rho_{\mathrm{w}}}{\rho_{\mathrm{a}}}\right)^{\frac{2}{3}}$.

Pinsky et al. (2012) showed that Eq. (A5) can be written in a non-dimensional form that results in a universal profile of supersaturation with height at given vertical velocity. The condition $\frac{\mathrm{d} S_{\mathrm{w}}}{\mathrm{d} z}=0$ applied to this equation allows obtaining a solution in the form (Eq. 1) for $S_{\max }$, as well as for the height of $S_{\max }$ over the cloud base. Pinsky et al. $(2012,2014)$ showed that Eq. (1) is valid for any size distributions of $\mathrm{CCN}$. 
Acknowledgements. The study is supported by the US Department of Energy Award DE_FOA-0000647 from the US Department of Energy Atmospheric System Research Program, by the Binational US-Israel Science Foundation (grant 2010446), and by the Israel Science Foundation (grant 1393/14).

Edited by: B. Ervens

Reviewed by: two anonymous referees

\section{References}

Abdul-Razzak, H. and Ghan, S. J.: A parameterization of aerosol activation: 2. Multiple aerosol types, J. Geophys. Res., 105, 6837, doi:10.1029/1999JD901161, 2000.

Abdul-Razzak, H., Ghan, S. J., and Rivera-Carpio, C.: A parameterization of aerosol activation: 1. Single aerosol type, J. Geophys. Res., 103, 6123, doi:10.1029/97JD03735, 1998.

Bedos, C., Suhre, K., and Rosset, R.: Adaptation of a cloud activation scheme to a spectral-chemical aerosol model, Atmos. Res., 41, 267-279, doi:10.1016/0169-8095(96)00014-2, 1996.

Benmoshe, N., Pinsky, M., Pokrovsky, A., and Khain, A.: Turbulent effects on the microphysics and initiation of warm rain in deep convective clouds: 2-D simulations by a spectral mixedphase microphysics cloud model, J. Geophys. Res., 117, D06220, doi:10.1029/2011JD016603, 2012.

Bigg, E. K.: The formation of atmospheric ice crystals by the freezing of droplets, Q. J. Roy. Meteor. Soc., 79, 510-519, doi:10.1002/qj.49707934207, 1953.

Bott, A.: A Flux Method for the Numerical Solution of the Stochastic Collection Equation, J. Atmos. Sci., 55, 2284-2293, doi:10.1175/1520-0469(1998)055<2284:AFMFTN>2.0.CO;2, 1998.

Cohard, J.-M., Pinty, J.-P., and Bedos, C.: Extending Twomey's Analytical Estimate of Nucleated Cloud Droplet Concentrations from CCN Spectra, J. Atmos. Sci., 55, 3348-3357, doi:10.1175/1520-0469(1998)055<3348:ETSAEO>2.0.CO;2, 1998.

Fountoukis, C.: Continued development of a cloud droplet formation parameterization for global climate models, J. Geophys. Res., 110, D11212, doi:10.1029/2004JD005591, 2005.

Freud, E. and Rosenfeld, D.: Linear relation between convective cloud drop number concentration and depth for rain initiation, J. Geophys. Res., 117, D02207, doi:10.1029/2011JD016457, 2012.

Ghan, S. J., Chung, C. C., and Penner, J. E.: A parameterization of cloud droplet nucleation part I: single aerosol type, Atmos. Res., 30, 198-221, doi:10.1016/0169-8095(93)90024-I, 1993.

Ghan, S. J., Leung, L. R., Easter, R. C., and Abdul-Razzak, H.: Prediction of cloud droplet number in a general circulation model, J. Geophys. Res., 102, 21777, doi:10.1029/97JD01810, 1997.

Ghan, S. J., Abdul-Razzak, H., Nenes, A., Ming, Y., Liu, X., Ovchinnikov, M., Shipway, B., Meskhidze, N., Xu, J., and Shi, X.: Droplet nucleation: Physically-based parameterizations and comparative evaluation, J. Adv. Model. Earth Syst., 3, M10001, doi:10.1029/2011MS000074, 2011.

Hallet, J. and Mossop, S. C.: Production of secondary ice particles during the riming process, Nature, 249, 26-28, doi:10.1038/249026a0, 1974.
Ilotoviz, E., Khain, A., Benmoshe, N., Phillips, V. T. J., and Ryzhkov, A.: Effect of aerosols on freezing drops, hail and precipitation in a mid-latitude storm, J. Atmos. Sci., 73, 109-144, doi:10.1175/JAS-D-14-0155.1, 2016.

Khain, A. P.: Notes on state-of-the-art investigations of aerosol effects on precipitation: A critical review, Environ. Res. Lett., 4, 015004, doi:10.1088/1748-9326/4/1/015004, 2009.

Khain, A. P. and Sednev, I. L.: Simulation of hydrometeor size spectra evolution by water-water, ice-water and ice-ice interactions, Atmos. Res., 36, 107-138, doi:10.1016/0169-8095(94)00030-H, 1995.

Khain, A. P., Ovtchinnikov, M., Pinsky, M., Pokrovsky, A., and Krugliak, H.: Notes on the state-of-the-art numerical modeling of cloud microphysics, Atmos. Res., 55, 159-224, doi:10.1016/S0169-8095(00)00064-8, 2000.

Khain, A. P., Pinsky, M., Shapiro, M., and Pokrovsky, A.: Collision Rate of Small Graupel and Water Drops, J. Atmos. Sci., 58, 2571-2595, doi:10.1175/15200469(2001)058<2571:CROSGA>2.0.CO;2, 2001.

Khain, A. P., Pokrovsky, A., Pinsky, M., Seifert, A., and Phillips, V.: Simulation of Effects of Atmospheric Aerosols on Deep Turbulent Convective Clouds Using a Spectral Microphysics Mixed-Phase Cumulus Cloud Model. Part I: Model Description and Possible Applications, J. Atmos. Sci., 61, 2963-2982, doi:10.1175/JAS-3350.1, 2004.

Khain, A. P., Benmoshe, N., and Pokrovsky, A.: Factors Determining the Impact of Aerosols on Surface Precipitation from Clouds: An Attempt at Classification, J. Atmos. Sci., 65, 1721-1748, doi:10.1175/2007JAS2515.1, 2008.

Khain, A. P., Rosenfeld, D., Pokrovsky, A., Blahak, U., and Ryzhkov, A.: The role of $\mathrm{CCN}$ in precipitation and hail in a mid-latitude storm as seen in simulations using a spectral (bin) microphysics model in a 2-D dynamic frame, Atmos. Res., 99, 129-146, doi:10.1016/j.atmosres.2010.09.015, 2011.

Khain, A. P., Phillips, V., Benmoshe, N., and Pokrovsky, A.: The Role of Small Soluble Aerosols in the Microphysics of Deep Clean Clouds, J. Atmos. Sci., 69, 2787-2807, doi:10.1175/2011JAS3649.1, 2012.

Khain, A. P., Beheng, K. D., Heymsfield, A., Korolev, A., Krichak, S. O., Levin, Z., Pinsky, M., Phillips, V., Prabhakaran, T., Teller, A., van den Heever, S. C., and Yano, J.-I.: Representation of microphysical processes in cloud-resolving models: spectral (bin) microphysics vs. bulk parameterization, Rev. Geophys., 53, 247322, 2015.

Khain, A. P., Lynn, B., and Shpund, J.: High Resolution WRF Simulations of Hurricane Irene: Sensitivity to Aerosols and Choice of Microphysical schemes, Atmos. Res., 167, 129-145, 2016.

Khvorostyanov, V. I. and Curry, J. A.: Aerosol size spectra and $\mathrm{CCN}$ activity spectra: Reconciling the lognormal, algebraic, and power laws, J. Geophys. Res., 111, D12202, doi:10.1029/2005JD006532, 2006.

Kogan, Y. L.: The simulation of a convective cloud in a 3-D model with explicit microphysics. Part I: Model description and sensitivity experiments, J. Atmos. Sci., 48, 1160-1189, 1991.

Meyers, M. P., DeMott, P. J., and Cotton, W. R.: New primary icenucleation parameterizations in an explicit cloud model, J. Appl. Meteor., 31, 708-721, 1992.

Phillips, V. T. J., Pokrovsky, A., and Khain, A.: The influence of time-dependent melting on the dynamics and precipitation pro- 
duction in maritime and continental storm clouds, J. Atmos. Sci., 64, 338-359, doi:10.1175/JAS3832.1, 2007.

Phillips, V. T. J., Khain, A., Benmoshe, N., Ryzhkov, A., and Ilotovich, E.: Theory of time dependent freezing. Part I: Description of scheme for wet growth of hail, J. Atmos. Sci., 71, 4527-4557, doi:10.1175/JAS-D-13-0375.1, 2014.

Phillips, V. T. J., Khain, A., Benmoshe, N., Ryzhkov, A., and Ilotovich, E.: Theory of timedependent freezing. Part II: Scheme for freezing raindrops and simulations by a cloud model with spectral bin microphysics, J. Atmos. Sci., 72, 262-286, doi:10.1175/JAS-D-13-0376.1, 2015.

Pinsky, M. and Khain, A. P.: Effects of in-cloud nucleation and turbulence on droplet spectrum formation in cumulus clouds, Q. J. Roy. Met. Soc., 128, 1-33, 2002.

Pinsky, M., Khain, A., and Shapiro, M.: Collision Efficiency of Drops in a Wide Range of Reynolds Numbers: Effects of Pressure on Spectrum Evolution, J. Atmos. Sci., 58, 742-764, doi:10.1175/1520-0469(2001)058<0742:CEODIA >2.0.CO;2, 2001.

Pinsky, M., Mazin, I., Korolev, A., and Khain, A.: Analytical estimation of droplet concentration at cloud base, J. Geophys. Res. 117, D18211, doi:10.1029/2012JD017753, 2012.

Pinsky, M., Mazin, I. P., Korolev, A., and Khain, A.: Supersaturation and diffusional droplet growth in liquid clouds, J. Atmos. Sci. 70, 2778-2793, 2013.

Pinsky, M., Mazin, I., Korolev, A., and Khain, A.: Supersaturation and diffusional droplet growth in liquid clouds: Polydisperse spectra, J. Geophys Res., 119, 12872-12887, 2014.
Pruppacher, H. R. and Klett, J. D.: Microphysics of Clouds and Precipitation, 2nd edn., Springer, New York, USA, 954 pp., 1997.

Rogers, R. R. and Yau, M. K.: A Short Course of Cloud Physics, Pregamon, Oxford, UK, 293 pp., 1989.

Rogers, R. R. and Yau, M. K.: Short Course in Cloud Physics, Butterworth-Heinemann, New York, USA, 304 pp., 1996.

Rotunno, R. and Klemp, J.: On the Rotation and Propagation of Simulated Supercell Thunderstorms, J. Atmos. Sci., 42, 271-292, doi:10.1175/15200469(1985)042<0271:OTRAPO>2.0.CO;2, 1985.

Segal, Y. and Khain, A. P.: Dependence of droplet concentration on aerosol conditions in different cloud types: application to droplet concentration parameterization of aerosol conditions, J. Geophys. Res., 111, D15204, doi:10.1029/2005JD006561, 2006.

Shipway, B. J. and Abel, S. J.: Analytical estimation of cloud droplet nucleation based on an underlying aerosol population, Atmos. Res., 96, 344-355, doi:10.1016/j.atmosres.2009.10.005, 2010.

Takahashi, T., Endoh, T., and Wakahama, G.: Vapor diffusional growth of free-falling snow crystals between 3 and $-23^{\circ} \mathrm{C}$, J. Meteorol. Soc. Jpn., 69, 15-30, 1991.

Tao, W.-K., Chen, J.-P., Li, Z., Wang, C., and Zhang, C.: Impact of Aerosols on Convective Clouds and Precipitation, Rev. Geophys., 50, RG2001, doi:10.1029/2011RG000369, 2012.

Vali, G.: Freezing rate due to heterogeneous nucleation, J. Atmos. Sci., 51, 1843-1856, doi:10.1175/15200469(1994)051<1843:FRDTHN>2.0.CO;2, 1994. 